\title{
Partidos e políticas públicas: o atendimento à infância em situação de risco em Ribeirão Preto-SP (1993-2000)
}

\author{
Political parties and public policies: dealing with children at riskful \\ situations in Ribeirão Preto, São Paulo (1993-2000)
}

\section{Gislayne Cristina Figueiredo Vasquez ${ }^{1}$ José Marcelino de Rezende Pinto ${ }^{2}$}

\section{Resumo:}

Uma discussão central noâmbito das políticas públicas refere-se à forma como as políticas públicas na área social se relacionam com o ideário dos partidos à frente da administração pública. Nesse trabalho, avaliamos o impacto da mudança de administração municipal em Ribeirão Preto no atendimento à infância em situação de risco, observando como o ideário político-partidário influenciou as políticas sociais. Para isso, analisamos os programas de governo dos partidos vencedores dos pleitos de 1992 (PT) e 1996 (PSDB) e as ações efetivamente realizadas para a área. Os resultados indicam que, enquanto a gestão do PT mostrou forte ênfase nas políticas sociais através da ação direta do poder público, a gestão do PSDB tinha como enfoque prioritário o desenvolvimento econômico e, embora não tenha reduzido os recursos para a área da infância, priorizou a sua aplicação através de entidades privadas (ONGs).

Palavras-chave: políticas públicas; políticas de atendimento; crianças e adolescentes em situação de risco; partidos políticos.

\begin{abstract}
:
The main discussion regarding public policies refers to how the public policies on the social area are related to goals of the different political parties in power and the administration of public affairs. This research evaluates the impact of the change of local administration in Ribeirão Preto in relation to dealing with children at riskful situations. The influence of the various goals of the political parties on the social policies was widely observed. In order to achieve such a purpose, the programs of the elected parties (elections: 1992 won by PT, and 1996 won by PSDB $^{*}$ ) and the actions taken on the specific area, were thoroughly analyzed. The conclusions of this research indicate that while the PT adminstration gave great emphasis to social policies through the direct action of the public power, the PSDB administration had as a priority goal, the economic development. Eventhough this party did not cut down financial resources for childhood programs, it was primarily done through private organizations.

* PT - Partido dos Trabalhadores (Workers Party), currently in power with Lula as President (since 2003). PSDB-Partido da Social Democracia Brasileira (Brazilian Social Democracy Party), political party in opposition to PT.
\end{abstract}

Key words: public policies; children and adolecents at riskful situations; politcal parties. 


\section{Introdução}

O Estado, segundo uma visão dialética da história, é o fator de coesão de uma dada formação social e tem o papel de garantir a reprodução das condições de produção do sistema onde está inserido que, por sua vez, determina a dominação de uma classe (ou fração de classe) sobre as demais (Poulantzas, 1977).

O Estado de Bem Estar Social foi uma forma de organização do Estado que surgiu no final do século XIX, quando nos países capitalistas ocidentais começa a ocorrer uma mudança na visão do papel do Estado, que passa a ser visto como tendo a função de intervir na realidade e dinâmica social, criando mecanismos e serviços que visassem o bem estar social das classes menos favorecidas e da sociedade como um todo. Sua consolidação se dá principalmente na década de 1930, após a crise mundial de 1929 (King, 1988).

Nos países desenvolvidos, o Estado de Bem Estar prosperou e se firmou até a década de 1970, quando uma crise mundial possibilitou o surgimento da chamada "Nova Direita" com suas proposições de reorganização do Estado. Essa proposta política tem sido conhecida como neoliberalismo (Draibe, 1993).

As prescrições neoliberais para o campo social advogam um teto máximo para a ação do Estado, pois segundo os autores que as defendem, o mercado é o melhor provedor de bem estar. O oferecimento de serviços pelo Estado, além de terem qualidade inferior aos oferecidos pelo mercado, é forte desestimulador ao trabalho, o que gera uma queda na produção, pois os beneficiários dessas políticas se acostumam a recebê-las de graça, e passam a não se esforçar para buscá-las no mercado (Faleiros, 2000; Draibe, 1993). Além disso, as políticas sociais seriam responsáveis pelo aumento do déficit público (Vianna, 1997).

As reformas neoliberais seguem as premissas de Estado mínimo, de descentralização, focalização e privatização. Essas prescrições, adotadas por vários países, levaram ao recrudescimento da pobreza, à escalada da violência social, à pauperização de contingentes cada vez maiores da população devido à diminuição de empregos. Esse aumento dos problemas sociais fez com que as políticas sociais voltassem a fazer parte da agenda de investimentos, numa segunda etapa de reformas (Faleiros, 2000; Draibe, 1993).

Muito tem sido dito acerca da política do Estado Mínimo e do desmonte do Estado de Bem Estar Social, mas estudos têm demonstrado que este processo não é tão profundo como se dizia, principalmente em se tratando de países capitalistas desenvolvidos (King, 1988; Draibe, 1993; Vianna, 1997).

O que as políticas de cunho liberalizante têm feito com sucesso é uma mudança na visão da função do Estado, e não propriamente um saneamento e redução dos gastos, que em alguns países vêm inclusive crescendo, sendo essa reforma, portanto, mais de cunho político e ideológico do que propriamente econômico, o que implica que a ideologia dos partidos que assumem a gestão pública se mostra altamente influente na manutenção de prioridades da agenda administrativa (Vianna, 1997).

Nos países de primeiro mundo, o espaço de sustentação do Estado de Bem Estar tem sido a arena política (Vianna, 1997). Uma forma de preservá-lo tem sido a eleição de políticos de partidos com propostas de preservação das políticas sociais (King, 1988). Segundo King (1988), a ideologia do partido que ascende ao poder é essencial para determinar seu apoio ou não ao Estado de Bem Estar Social. Além disso, segundo Viana (1988), os partidos políticos são um dos atores não governamentais que mais afetam a construção de investimentos e prioridades públicas, e os períodos de mudança na administração pública também se mostram extremamente importantes, já que são nesses momentos que as mudanças no curso e na direção das políticas acontecem.

No Brasil e no restante da América Latina, o período de suposto desmonte do Estado de Bem Estar Social coincidiu com a época de redemocratização e de uma maior participação popular no cenário político, o que permitiu a 
organização de um Estado com tendências a se preocupar com o social (Draibe, 1993). Porém, como coloca Silva (1998, p. 35),

da possibilidade de um modelo de Proteção Social do tipo institucional, contemplado, em parte, na Constituição de 1988, o Brasil tem caminhado em direção a um modelo residual de proteção institucional, sobretudo a partir de 1995, quando a gestão de governo, eleita em 1994, passa a se empenhar nas reformas do Estado.

A Constituição de 1988, promulgada em um período de abertura política, teve uma participação bastante intensa da sociedade civil organizada na elaboração de seus princípios, o que possibilitou que esta incorporasse vários direitos sociais. Nesse mesmo cenário, e influenciado pelas mesmas forças, surgiu em 1990, pela lei 8.069/90 o ECA - Estatuto da Criança e do Adolescente, que passa a dar as diretrizes para as políticas públicas de atendimento a crianças e adolescentes no Brasil, revogando o Código de Menores de 1979.

No entanto, a evolução representada pela Constituição Federal de 1988 e pelo ECA foi acompanhada de uma diminuição no investimento na área social, incluindo aí o atendimento à infância. Essa diminuição de investimentos, aliada ao incremento da violência social, acaba reforçando a ideologia que se manteve durante toda a história das políticas sociais à infância: a associação entre pobreza e criminalidade (Passetti, 1999).

É importante assinalar que tanto a prática quanto os discursos oficiais a respeito da criança e de sua situação social ao longo da história não têm demonstrado uma preocupação de refletir acerca dos motivos que levam a criança a estar em situação de risco, o que tem como consequência a criação de mais programas de reinserção social e de ação protetora do que programas de prevenção (Pilotti, 1994).

Diante do acima exposto, essa pesquisa buscou verificar qual o impacto da mudança na administração municipal de Ribeirão Preto, em virtude das eleições de 1996, na área de políticas sociais, com enfoque especial no setor de atenção à infância e adolescência em situação de risco na cidade. Pretendíamos com isso analisar as principais diferenças entre os programas de governo e da prática das gestões municipais de 1993 a 1996 (PT) e de 1997 a 2000 (PSDB) para a área de Assistência Social, bem como os programas dos respectivos partidos; verificar e comparar os gastos para a área de Assistência Social das duas gestões; e buscar, numa primeira aproximação, observar como o ideário político, consubstanciado em um programa de governo, se traduz em realidade no atendimento municipal.

O tema desse artigo tem se mostrado importante não só porque o impacto da mudança de governos na política social e no próprio funcionamento do estado é um tema discutido no mundo todo, mas principalmente por causa de sua atualidade no cenário nacional, ao poder contribuir com a discussão da conjuntura de mudança político-partidária que o país está vivendo no cenário federal, e com reflexões acerca da mudança (ou não) das prioridades e dos investimentos nas políticas sociais.

\section{Essa Pesquisa}

Nopresenteestudo, emfunçãodacaracterística dos dados levantados - eminentemente históricos e impressos, optamos por utilizar a análise documental como técnica de pesquisa. Esta técnica foi escolhida devido ao fato de ser a mais adequada para aplicação em dados históricos, permitindo um estudo longitudinal baseado em uma fonte mais exata e estável do que as percepções subjetivas dos atores envolvidos no processo (Ludke e André, 1986).

Os dados escolhidos como fonte de pesquisa foram os dos tipos oficial e técnico, a saber:

programas políticos e manifestos de fundação dos partidos à frente das coligações que assumiram as gestões municipais nos anos de 1993 e 1997;

programas dos governos eleitos nas duas gestões referidas;

publicações oficiais da Secretaria de Bem Estar Social (gestão 1993-1996) e da Secretaria de Cidadania e Desenvolvimento 
Social (gestão 1997-2000) sobre seus programas de atendimento;

- relatórios de atendimento da Secretaria de Bem Estar Social e da Secretaria de Cidadania e Desenvolvimento Social;

- dados sócio-demográficos da cidade de Ribeirão Preto;

- balanços orçamentários e financeiros anuais do período de 1993 a 2000.

- Com esses dados foi realizada uma análise dos investimentos públicos municipais na área social, bem como uma análise de conteúdo dos dados qualitativos.

- Osdadosforamanalisadosemtrêsgrandes conjuntos, que foram posteriormente comparados:

- programas, manifestos, estatutos e material de formação dos partidos:

- programas de governo das coligações eleitas;

- reformas administrativas promovidas pelas gestões, dados dos gastos públicos e os números de atendimento das administrações em termos de programas destinados à infância e adolescência em situação de risco.

\section{O ideário político dos partidos (PT e PSDB)}

A análise dos Programas e Manifestos de Fundação dos partidos (PT, 1980; PSDB, 1988) revelou que estes discorrem sobre os mesmos assuntos, sob enfoques diferentes e às vezes contrários.

Questões como democracia, liberdades pessoais, participação popular, relações externas, políticas públicas, são vistas como importantes por ambos os partidos, mas eles entendem essas questões sob pontos de vista diferentes, com ênfases diferentes, bem como com causas e formas de solução diferentes para seus problemas.

A única questão onde parece haver confluência de opiniões é a descentralização, que ambos os partidos vêem como positiva por entenderem que possibilita uma maior participação popular na gestão pública - ainda que os dois partidos entendam participação popular sob enfoques diferentes.

\section{Quadro 1: Posições político-partidárias do PT e do PSDB}

\begin{tabular}{|c|c|c|}
\hline & PT & PSDB \\
\hline 1- 0 partido & $\begin{array}{l}\text { - nasce da vontade } \\
\text { de organização dos } \\
\text { trabalhadores. }\end{array}$ & $\begin{array}{l}\text { - nasce porque os } \\
\text { políticos não viam } \\
\text { condições de defender } \\
\text { aquilo que acreditavam } \\
\text { dentro do quadro } \\
\text { partidário de então. }\end{array}$ \\
\hline $\begin{array}{l}\text { 2- } \\
\text { Participação } \\
\text { popular }\end{array}$ & $\begin{array}{l}\text { - participação direta } \\
\text { dos trabalhadores nas } \\
\text { decisões políticas, } \\
\text { - participação na luta } \\
\text { por direitos sociais, } \\
\text { - organização dos } \\
\text { trabalhadores } \\
\text { enquanto força } \\
\text { política autônoma. }\end{array}$ & $\begin{array}{l}\text { - sociedade civil } \\
\text { organizada; } \\
\text { - participação através } \\
\text { de organizações; } \\
\text { - participação na } \\
\text { gestão estatal, } \\
\text { definição de gastos e } \\
\text { políticas públicas. }\end{array}$ \\
\hline $\begin{array}{c}3- \\
\text { Democracia }\end{array}$ & $\begin{array}{c}\text { - ênfase na } \\
\text { democracia direta. }\end{array}$ & $\begin{array}{c}\text { - ênfase na } \\
\text { democracia indireta } \\
\text { (representativa). }\end{array}$ \\
\hline 4- Reformas & $\begin{array}{l}\text { - transformação do } \\
\text { estado. }\end{array}$ & - reforma do estado. \\
\hline 5- Exclusão & $\begin{array}{l}\text { - fruto do sistema } \\
\text { capitalista; } \\
\text { - solução: superação } \\
\text { deste regime. }\end{array}$ & $\begin{array}{c}\text { - fruto da crise } \\
\text { econômica; } \\
\text { - solução: crescimento } \\
\text { econômico e } \\
\text { redistribuição de renda. }\end{array}$ \\
\hline $\begin{array}{l}\text { 6- Políticas } \\
\text { públicas }\end{array}$ & $\begin{array}{c}\text { - definição popular; } \\
\text { - interesses } \\
\text { trabalhadores x } \\
\text { interesses elite. }\end{array}$ & $\begin{array}{l}\text { - menos ênfase na } \\
\text { participação popular. }\end{array}$ \\
\hline $\begin{array}{l}\text { 7- Lutas } \\
\text { sociais e } \\
\text { reivindicações } \\
\end{array}$ & $\begin{array}{l}\text { - questões imediatas e } \\
\text { questões mais amplas } \\
\text { do sistema capitalista. }\end{array}$ & $\begin{array}{c}\text { - lutas por reforma } \\
\text { do estado. }\end{array}$ \\
\hline 8- Liberdade & $\begin{array}{c}\text { - inalienável; } \\
\text { - inclui direitos } \\
\text { pessoais, de } \\
\text { organização e ausência } \\
\text { de problemas sociais. }\end{array}$ & $\begin{array}{l}\text { - inalienável; } \\
\text { - direito de pensar, } \\
\text { falar, à segurança e à } \\
\text { defesa pessoal. }\end{array}$ \\
\hline $\begin{array}{l}\text { 9- Papel do } \\
\text { Estado }\end{array}$ & $\begin{array}{c}\text { - deve ser a expressão } \\
\text { da sociedade, } \\
\text { majoritariamente } \\
\text { composta por } \\
\text { trabalhadores. }\end{array}$ & $\begin{array}{c}\text { - estimular a } \\
\text { produção; } \\
\text { - contribuir para o } \\
\text { bem-estar. }\end{array}$ \\
\hline $\begin{array}{l}\text { 10- Relações } \\
\text { internacionais }\end{array}$ & $\begin{array}{c}\text { - atualmente: } \\
\text { dependência } \\
\text { econômica, } \\
\text { tecnológica e cultural; } \\
\text { - dívida externa: } \\
\text { fruto da atual relação } \\
\text { internacional. } \\
\end{array}$ & $\begin{array}{l}\text { - possibilidade de } \\
\text { inserção soberana no } \\
\text { cenário internacional; } \\
\text { - dívida externa: deve } \\
\text { ser paga de uma } \\
\text { forma a garantir a } \\
\text { soberania nacional. }\end{array}$ \\
\hline $\begin{array}{c}11- \\
\text { Capitalismo } \\
\text { (sistema } \\
\text { capitalista) } \\
\end{array}$ & $\begin{array}{l}\text { - necessidade de } \\
\text { superação. }\end{array}$ & $\begin{array}{l}\text { - base do sistema } \\
\text { econômico brasileiro. }\end{array}$ \\
\hline $\begin{array}{l}\text { 12- } \\
\text { Redistribuiçãa } \\
\text { de renda }\end{array}$ & $\begin{array}{l}\text { - associada à } \\
\text { mudança do modelo } \\
\text { econômico. }\end{array}$ & $\begin{array}{c}\text { - deve dar-se em } \\
\text { conjunto com o } \\
\text { crescimento econômico. }\end{array}$ \\
\hline $\begin{array}{c}13- \\
\text { Descentralização }\end{array}$ & - a favor. & - a favor. \\
\hline $\begin{array}{c}14- \\
\text { Privatização }\end{array}$ & - contra & - a favor. \\
\hline
\end{tabular}


Podemos observar que a posição teórica em que se baseou o PT para a construção do seu ideário político é a de matriz Marxista, cujo objetivo é a superação do atual modo de produção capitalista para um novo onde não haja exclusão social, tendo a participação popular e as lutas e reivindicações por base.

Já o PSDB teve como base teórica o liberalismo e a social democracia, oscilando entre essas duas referências. Daí podemos entender sua ênfase nas reformas do Estado e sociais, e certo pragmatismo com relação às políticas públicas.

\section{A assistência social em Ribeirão Preto e o atendimento à criança e ao adolescente em situação de risco.}

a) Os programas de Governo.

O Programa da gestão 1993-1996 (prefeito Antonio Palocci Filho - PT; vice Joaquim Rezende - PSDB), ainda que representasse uma síntese do trabalho de vários partidos (PT, PSDB, PSB, PPS, e PV), deu enfoque à questão da participação popular, trabalhou com o conceito de exclusão social, com a importância de fomentar a organização da sociedade civil. Isto fez com que o Programa se aproxime das teses políticas colocadas no Manifesto e no Programa Partidário do partido que encabeça a coligação, o PT.

No entanto, notamos no Programa de Governo a ausência de temas aos quais se dá muita ênfase no Programa e no Manifesto Partidário do PT, assuntos esses como a necessidade de superação do capitalismo e as lutas e reivindicações dos trabalhadores.

Por outro lado, notamos a presença de assuntos antes não muito presentes no vernáculo da esquerda, como parcerias e relação com a iniciativa privada.

Já com relação ao Programa da gestão 19972000 (prefeito Luis Roberto Jábali e vice Delvita Pereira Alves, ambos do PSDB), os três temas acerca dos quais este discorre são: tecnologia, administração pública e desenvolvimento econômico.

É perceptível nestes tópicos uma visão empresarial sobre a administração. Essa visão perpassa inclusive as políticas públicas. Há uma ênfase na questão do desenvolvimento empresarial, da atração de novas empresas para a cidade, da elevação do nível da qualidade das empresas já situadas no município.

Isso vai inclusive ao encontro do proposto no Programa Partidário e no Manifesto do partido que encabeçava a coligação Frente Social Democrática, o PSDB, que é a de que o desenvolvimento social só pode se dar se for precedido e sustentado pelo desenvolvimento econômico.

Já questões como exclusão social e participação popular não são muito citadas, apesar de estarem presentes no Programa e no Manifesto do Partido.

Assim, embora o ideário presente no Programa e no Manifesto do partido possa ter em alguns pontos de proximidade com a social democracia, o Programa de Governo se aproximou mais de uma posição neoliberal.

b) O atendimento à criança e ao adolescente em Ribeirão Preto

A participação da municipalidade no atendimento à criança e adolescente em situação de risco em Ribeirão Preto se inicia por meio de convênios com a iniciativa privada.

Paulatinamente, o poder público municipal passou a realizar os atendimentos às crianças e adolescentes em situação de risco, até chegar, nos anos 1990, a ser o principal prestador de serviços nesta área.

No final de 1992, o poder público municipal contava com seis programas de atendimento à criança e ao adolescente em situação de risco pessoal e social, a saber: Núcleos de Atendimento à Criança e ao Adolescente; Programa Plantão Social; Programa de Intercâmbio; Programa Casa Abrigo à Criança Vitimizada; Centro SócioPedagógico e Núcleo Especial do Horto. Estes programas contemplavam $\mathrm{O}$ atendimento a crianças vitimizadas, a crianças com vivência de rua e a crianças de classes sócio-econômicas menos privilegiadas, residentes em bairros periféricos da cidade.

O quadro 2 nos mostra os programas de atendimento à infância em situação de risco, 
bem como às suas famílias. Podemos perceber que houve um salto quantitativo em relação aos programas que existiam antes da gestão PT. Eram 6 programas no final de 1992, foram criados 13 programas na administração PT, chegando esta a ficar com 19 programas de atendimento a esta clientela. No final da gestão PT foram desativados 3 programas.

\section{Quadro 2: Programas existentes e} criados pelas administrações PT e PSDB

\begin{tabular}{|c|c|c|}
\hline PROGRAMAS & Gestão PT & Gestão PSDB \\
\hline \multicolumn{3}{|c|}{ Programas complementares à educação formal } \\
\hline Núcleos & Manteve-se & Manteve-se \\
\hline $\begin{array}{l}\text { Programa Ribeirão } \\
\text { Criança }\end{array}$ & Criado & Manteve-se \\
\hline \multicolumn{3}{|c|}{ Programas de Atendimento Inicial } \\
\hline Plantão social & Manteve-se & Manteve-se \\
\hline Programa de recâmbio & Manteve-se & Manteve-se \\
\hline Disque-criança & Criado & Manteve-se \\
\hline $\begin{array}{c}\text { SAC (Serviço de } \\
\text { Atendimento à Criança) }\end{array}$ & $\begin{array}{l}\text { Criado/ } \\
\text { desativado } \\
\text { em } 95\end{array}$ & ------ \\
\hline \multicolumn{3}{|c|}{ Programas de Intervenção Direta e Continuada } \\
\hline $\begin{array}{c}\text { Casa abrigo - CACAV } \\
\text { (Centro de Atendimento } \\
\text { à Criança e ao } \\
\text { Adolescente Vitimizado) }\end{array}$ & Manteve-se & Manteve-se \\
\hline $\begin{array}{c}\text { Grupo de Atendimento } \\
\text { Familiar }\end{array}$ & Criado & Manteve-se (PAOF) \\
\hline $\begin{array}{l}\text { Centro sócio- } \\
\text { pedagógico }\end{array}$ & Manteve-se & Desativado \\
\hline $\begin{array}{c}\text { Prog. Acompanhamento } \\
\text { a vitimizados }\end{array}$ & Criado & Desativado \\
\hline $\begin{array}{c}\text { Prog. de atendimento } \\
\text { às famílias de abrigados }\end{array}$ & Criado & Desativado \\
\hline Oficina terapêutica & Criado & Desativado \\
\hline Pedagogia de Rua & Criado & Manteve-se \\
\hline Núcleo do Horto & Manteve-se & $\begin{array}{l}\text { Atividades } \\
\text { suspensas }\end{array}$ \\
\hline Casa Dormitório & $\begin{array}{l}\text { Criado/ } \\
\text { desativado } \\
\text { em } 96\end{array}$ & ------ \\
\hline Casa Aberta & $\begin{array}{c}\text { Criado/ } \\
\text { desativado } \\
\text { em } 96 \\
\end{array}$ & ----- \\
\hline Casa Travessia & Criado & Manteve-se \\
\hline $\begin{array}{l}\text { Prog. de medidas } \\
\text { sócio-educativas }\end{array}$ & Criado & Manteve-se \\
\hline \multicolumn{3}{|c|}{ Programas de Repasse de Recursos } \\
\hline $\begin{array}{l}\text { Prog. Auxílio à Família } \\
\text { Substituta }\end{array}$ & Criado & Manteve-se \\
\hline $\begin{array}{c}\text { PMAFFCACRM - Prog. } \\
\text { Munic. de Atendimento } \\
\text { Financeiro às Famílias } \\
\text { de Crianças e } \\
\text { Adolescentes Carentes } \\
\text { de Recursos Materiais }\end{array}$ & ----- & Criado \\
\hline
\end{tabular}

Fonte: Relatórios de atendimento/ textos da reorganização da SEBES/SCDS.
A gestão PSDB recebeu então uma SEBES com 16 programas de atendimento à infância em situação de risco. Foi criado mais 1 programa, e 5 tiveram suas atividades suspensas ou encerradas, ficando a administração com 12 programas.

Há que se considerar ainda que além desses 12 programas, os de complementação de renda a famílias com crianças e adolescentes em situação de risco, eram contemplados por outros programas que estavam fora da divisão de atendimento à criança, como o Instituto de Assuntos da Família (IAFAM), o Núcleo de Atendimento Familiar (NAF) e o Programa Renda Mínima, este último ligado diretamente ao gabinete do prefeito. Esses programas também foram descontinuados ou tiveram seu atendimento diminuído na gestão PSDB.

\section{Tabela 1: Tabela comparativa do atendimento à criança $e$ ao adolescente em situação de risco pela SEBES/SCDS nos anos de 1995 e 1999.}

\begin{tabular}{|c|c|c|}
\hline & 1995 & 1999 \\
\hline \multicolumn{3}{|c|}{ Programas complementares à educação formal } \\
\hline Núcleos & $\begin{array}{c}1291 \\
\text { atendidos/ano }\end{array}$ & $\begin{array}{l}1280 \text { atendidos/ } \\
\text { ano }\end{array}$ \\
\hline Programa Ribeirão Criança & ---- & Não consta \\
\hline \multicolumn{3}{|c|}{ Programas de Atendimento Inicial } \\
\hline SAC & 8/mês & ---- \\
\hline Disque-criança & 172/mês & 229/mês \\
\hline Programa de recâmbio & 18/mês & 20/mês \\
\hline Programa Plantão social & Não consta & 87/mês \\
\hline Total parcial & 198/mês & 336/mês \\
\hline \multicolumn{3}{|c|}{ Programas de Intervenção Direta e Continuada } \\
\hline Casa abrigo (CACAV) & 26/mês & 21/mês \\
\hline $\begin{array}{l}\text { Oficina terapêutica } \\
\text { (CACAV) }\end{array}$ & 8/mês & ---- \\
\hline GAP (CACAV)/PAOF & 24/mês & 47 famílias/mês \\
\hline $\begin{array}{l}\text { Prog. acompanhamento a } \\
\text { vitimizados }\end{array}$ & 62/mês & ---- \\
\hline $\begin{array}{l}\text { Pedagogia de Rua } \\
\text { (ACASR) }\end{array}$ & 239/mês & 177/mês \\
\hline Núcleo do Horto (ACASR) & 60/mês & $-\cdots$ \\
\hline Casa Dormitório (ACASR) & 49/mês & $\begin{array}{cl}--- \\
-\cdots\end{array}$ \\
\hline Casa Aberta (ACASR) & 63/mês & --- \\
\hline Casa Travessia (ACASR) & 9/mês & 16/mês \\
\hline Medidas sócio-educativas & --- & 31/mês \\
\hline Total parcial & 540/mês & 292/mês \\
\hline \multicolumn{3}{|c|}{ Programas de Repasse de Recursos } \\
\hline PMAFFCACRM & ---- & 68/mês \\
\hline $\begin{array}{l}\text { Programa Auxílio à Família } \\
\text { Substituta }\end{array}$ & * & 39/mês \\
\hline Total parcial & --- & 107/mês \\
\hline TOTAL & 738/mês & 735/mês \\
\hline
\end{tabular}

Fonte: relatórios de atendimento da SEBES/SCDS.

* Programa desenvolvido pelo COMDECA, não constam dados no relatório. 
Um ponto interessante de ser notado é que durante a gestão 1993-1996 se estruturaram os Conselhos Municipais com participação popular, como o Conselho Municipal de Defesa da Criança e do Adolescente. Esses Conselhos são fruto do avanço representado pela Constituição Federal, e preconizam a participação da sociedade na definição, implantação e acompanhamento das políticas públicas nos níveis municipal, estadual e federal. Pela tabela 1, percebemos que no ano de 1995, o COMDECA, já estruturado, prestava um serviço de auxílio à família, que posteriormente, como podemos observar no ano de 1999, foi incorporado pelo poder público.

Com relação ao número de atendimentos, calculados com os dados que constam nos relatórios (tabela 1), o número de atendimentos foi semelhante: excluindo o número de atendimentos feitos pelos Núcleos, que contabilizavam o número de crianças atendidas ao longo do ano e não a média mensal, a gestão PT prestou uma média de 738 atendimentos por mês, enquanto a gestão PSDB atendeu em média 735 crianças por mês.

No entanto, como podemos perceber pela tabela 1, a gestão do PT realizou a maioria dos seus atendimentos por meio de programas de intervenção direta e continuada junto à criança e ao adolescente vitimizado e à sua família, como a Pedagogia de Rua, a Casa Aberta ou o Núcleo do Horto, programas com uma proposta pedagógica definida, e que visavam à reinserção social dessa criança. Como já dito anteriormente, os programas de repasse de recursos para famílias de crianças e adolescentes em situação de risco estavam ligados a outras Secretarias Municipais ou diretamente ao Gabinete do Prefeito, e não foram contabilizados nesse trabalho.

Já a gestão levada a cabo pelo PSDB prestou mais atendimentos de cunho inicial ou de repasse de verbas, como o disque-criança, serviço que recebia denúncias de maus-tratos, e o PMAFFCACRM, que repassava recursos às famílias em situação de risco.

Assim, comparando o número de atendimentos prestados por programas de intervenção direta e continuada, a gestão 1993-1997 prestou 540 atendimentos continuados à criança e à sua família, enquanto a gestão 1997-2000 prestou 292 atendimentos, um total 46 \% menor em relação à gestão anterior.

Se, por um lado, houve uma diminuição do número de atendimentos diretos e continuados à criança e ao adolescente em situação de risco e à sua família, com vistas à reinserção social dos primeiros, os dados de investimento e atendimento indicam uma direção interessante:

Tabela 2: Gastos municipais no programa 81 (Assistência Social), em valores de moeda corrente e em percentagem. R\$ x 1000.

\begin{tabular}{|c|c|c|c|c|c|}
\hline & 1995 & 1996 & 1997 & 1998 & 1999 \\
\hline $\begin{array}{c}\text { Despesa } \\
\text { total }\end{array}$ & 164.666 & 247.617 & 237.445 & 278.374 & 284.667 \\
\hline $\begin{array}{c}\text { Gastos no } \\
\text { programa } \\
81\end{array}$ & 3.615 & 6.252 & 7.855 & 8.602 & 9.028 \\
\hline$\%$ & 2.20 & 2.52 & 3.31 & 3.09 & 3.17 \\
\hline
\end{tabular}

Fonte: Balanços orçamentários da Prefeitura Municipal de Ribeirão Preto (1995-1999).

Observando a tabela acima, podemos notar que os gastos com o programa de assistência social vêm num crescendo, demonstrando que o investimento na área social foi maior na última gestão estudada (PSDB) do que na primeira (PT).

Salientamos que os gastos do ano de 1997, realizados no primeiro ano da administração PSDB e que representam um salto em relação ao ano de 1996, foram orçados no último ano da administração anterior (PT), e podem indicar uma tentativa de se garantir o gasto na área social. Podemos observar que nos anos seguintes, os valores gastos na área social praticamente estacionaram nesse patamar $( \pm 3,1 \%)$.

\section{Tabela 3: Perfil das Despesas da Secretaria (SEBES/SCDS) segundo a sua natureza ( $\%$ do total)}

\begin{tabular}{|c|c|c|c|c|c|}
\hline & 1995 & 1996 & 1997 & 1998 & 1999 \\
\hline Pessoal & 64,3 & 68,3 & 73,1 & 58,6 & 58,0 \\
\hline Material de consumo & 10,7 & 11,6 & 7,9 & 8,4 & 7,6 \\
\hline Serviço de terceiros & 10,6 & 8,9 & 7,7 & 20,6 & 19,6 \\
\hline $\begin{array}{c}\text { Transferências } \\
\text { intragovernamentais }\end{array}$ & 0,0 & 0,0 & 0,0 & 0,0 & 0,0 \\
\hline $\begin{array}{c}\text { Transferências a } \\
\text { instituições privadas }\end{array}$ & 6,9 & 8,8 & 9,4 & 11,3 & 13,3 \\
\hline Despesa de capital & 7,5 & 6,2 & 1,9 & 1,0 & 1,6 \\
\hline Transferência de capital & 0,0 & 0,0 & 0,0 & 0,0 & 0,0 \\
\hline Total & $100 \%$ & $100 \%$ & $100 \%$ & $100 \%$ & $100 \%$ \\
\hline
\end{tabular}

Fonte: Balanços orçamentários da Prefeitura Municipal de Ribeirão Preto (1995-1999). 
A tabela 3 demonstra que os gastos com serviços de terceiros e o repasse para instituições privadas cresceu da gestão PT para a gestão PSDB, indo o valor porcentual dos investimentos da secretaria com serviços de terceiros de 10,6\% no ano de 1995 para 19,6\% em 1999; e o repasse para instituições privadas foi de $6,9 \%$ no ano de 1995 para 13,3\% em 1999, indicando realmente a direção de aumento de parcerias como terceiro setor para prestação de serviços à infância em situação de risco, financiadas com receitas públicas.

\section{Considerações finais}

A alternância de partidos à frente da gestão do Estado não só é um fato, quanto é condição necessária para a manutenção da democracia no atual modelo político vigente no país. Por outro lado, essas mudanças de gestão podem causar rupturas e descontinuidades que podem prejudicar - desenvolvimento das políticas públicas, principalmente daquelas voltadas às camadas mais economicamente fragilizadas da população.

No caso da mudança de gestão municipal ocorrida no início de 1997, podemos notar que há efetivamente uma ruptura e uma descontinuidade no atendimento à criança e ao adolescente. Equipamentos existentes foram fechados, e a direção norteadora da intervenção foi mudada. Os programas também não demonstraram ter muita força de sustentação junto à população, excetuando-se os Núcleos da Criança e do Adolescente, o que permitiu o fácil desmonte dessas instituições ou mudanças repentinas na direção do atendimento e na organização da rede de atendimento, sem maiores repercussões e perdas políticas.

Outro ponto interessante de se notar é que o ideário político dos partidos que ascendem ao poder realmente parece interferir na direção que a agenda pública irá tomar, na decisão de prioridades para as políticas de atenção municipal, na forma de organização e na visão da relação poder público $\mathrm{x}$ sociedade civil.

$\mathrm{O}$ ideário político dos dois partidos à frente da administração municipal, em cada um dos períodos estudados, era diferente.
O PT, que possuía na época em que foi eleito (1993) um ideário de cunho mais socialista, apresentou um discurso e uma prática que mais se aproximaram de uma visão social democrata. Tal prática esteve em sintonia com as mudanças posteriormente realizadas no próprio Programa do Partido (1999), que discorre sobre assuntos não tratados no primeiro Programa, datado de 1980, como reformas e preocupação com questões econômicas, entre outros. Por outro lado, na gestão PT, a participação popular era a grande tônica do discurso político, e percebemos que nessa gestão é que se estruturaram os Conselhos, como o CMDCA e os Conselhos Tutelares, entre outros.

A administração PSDB, com uma visão de um Estado menos intervencionista, caminhou no sentido de diminuir a prestação de serviços pelo poder público, delegando a realização dos atendimentos à sociedade civil, e cabendo ao poder público a função de financiador das políticas, mais do que executor.

Isso reporta ao que Vianna (1997) coloca como sendo a verdadeira intenção reformadora do neoliberalismo: a mudança na visão do papel do Estado, e não precisamente um enxugamento nos seus gastos. Segundo a autora, que estuda o investimento social em países desenvolvidos, não há um decréscimo no valor do investimento público, eles continuam a crescer, só que num ritmo menor (Vianna, 1997).

Os dados levantados por essa pesquisa vão nessa direção: houve um crescimento do investimento na área de assistência social, e também na área da infância em situação de risco. No entanto, estes gastos não se refletiram em mais serviços prestados pelo poder público, isto é, há um aumento dos gastos, mas esse não vem acompanhado de uma maior prestação de serviços para essa clientela, ao contrário, houve uma diminuição do número de atendimentos de programas de intervenção direta e continuada feitos pelo poder público para essa população, o que indica uma diminuição do tamanho do Estado em Ribeirão Preto.

A diminuição da prestação de serviços por parte do Estado está mais afinada com as 
políticas de cunho neoliberal da primeira fase, que pregam um desmonte dos programas de atenção social, pois segundo eles o gasto social é um dos componentes do déficit público.

Aalternativa dada pelas políticas neoliberais, para incrementar e dar continuidade ao atendimento social à população foi a de substituir intervenções diretas realizadas por instituições públicas, por aquelas efetivadas por meio de parceiras com a iniciativa privada ou por ONGs (Organizações NãoGovernamentais) e OSCIPs (Organizações da Sociedade Civil de Interesse Público).

O modelo de convênios e parcerias com entidades particulares é o mesmo com o qual se iniciou $\mathrm{o}$ atendimento à infância na cidade e no país, e que foi lentamente sendo deixado de lado, um pouco devido à instabilidade dos serviços, que se criam e são fechados facilmente, bem como à total dependência destas entidades dos recursos públicos para sobreviverem. Para essas entidades, a assistência é vista como caridade e tem motivações religiosas, muitas vezes não sendo vista como um direito do cidadão.

Semelhante ao que foi encontrado em Ribeirão Preto, o modelo de atenção à criança e ao adolescente do início do século no Brasil consistia em convênios e parcerias onde particulares entravam com a prestação do serviço, enquanto o governo entrava com o financiamento e incentivos (Lamamoto e Carvalho, 2000; Passetti, 1999).

No caso de Ribeirão Preto, podemos notar que $\mathrm{O}$ atendimento às crianças e adolescentes em situação de risco tem ficado cada vez mais sob responsabilidade dos serviços particulares.

A administração 1993-1996 privilegiou o mecanismo das parcerias com instituições privadas. No entanto, como pudemos observar, com o final dos convênios, os programas ficaram praticamente sem funcionários, além de terem seu desmonte facilitado em função da instabilidade que esses convênios apresentam. As parcerias, apesar de representarem uma possibilidade de gastos maior com o atendimento social, também representam a fragilização dos serviços.

Deste modo, o PT, apesar de criar vários e novos programas de atenção à infância, não criou mecanismos de fortalecimento desses programas, seja pela não institucionalização dos mesmos, seja pela não criação de uma estrutura mais estável para eles, ao não fortalecer a esfera pública.

Esse fortalecimento passaria por um aumento da máquina estatal - como, por exemplo, a realização de concursos públicos para contratação de funcionários estáveis, o que não foi realizado.

Como já dissemos, a gestão 1997-2000 ampliou o processo de privatização da prestação de serviços de atendimento à criança e ao adolescente em situação de risco tendo, além de aumentado o repasse para instituições privadas, diminuído a prestação direta de serviços pelo poder público.

Contudo, apesar do aumento dos gastos públicos com o financiamento do atendimento prestado por ONGs e outras entidades em Ribeirão Preto, não houve um aumento significativo no número dessas entidades para atender a população.

Além disso, como salienta Rosemberg (1994), não há ainda conhecimento suficiente sobre o funcionamento dessas instituições, sua inserção no atendimento e sua eficácia, os quais o discurso neoliberal diz serem superiores aos serviços prestados pelo Estado. Em Ribeirão Preto, o relatório de atendimento à infância em situação de risco não faz menção à forma de acompanhamento dos atendimentos realizados por essas Organizações, nem sobre o aspecto quantitativo, nem sobre o qualitativo.

No entanto, o fato mais preocupante com relação às entidades filantrópicas, é que não há parceria destas entidades com o poder público, mas o contrário, os recursos públicos é que mantém estas entidades sem, contudo, poder influenciar em suas políticas.

O que transparece da discussão aqui realizada é a necessidade de construção de mecanismos de controle social associados ao fortalecimento institucional desses programas, a fim de evitar os desmontes e rupturas nas políticas públicas observados nesta pesquisa e que ajudam a explicar a sua pouca efetividade. 


\section{Referências Bibliográficas}

DRAIBE, S. As políticas sociais e o neoliberalismo. Revista USP, São Paulo, 17, 86-101, 1993.

FALEIROS, V.P. A política social do estado capitalista. São Paulo, Cortez Editora, 2000.

IAMAMOTO, M. e CARVALHO, R. Relações sociais e serviço social no Brasil: esboço de uma interpretação histórico-metodológica. São Paulo: Cortez editora, 2000.

KING, D.S. O estado e as estruturas sociais de bem-estar em democracias industriais avançadas. Novos Estudos CEBRAP, 22, 53-76, 1998.

LUDKE, M. e ANDRÉ, M.E.D. Pesquisa em educação: abordagens qualitativas. São Paulo, EPU, 1986.

LULA, L.I.S. Carta ao povo brasileiro. In: www.pt.org.br/25anos. Acesso em 11 de fevereiro de 2005.

PASSETTI, E. Crianças carentes e políticas públicas. Em M.D. Priore, História das crianças no Brasil. São Paulo, Editora Contexto, 1999.

PILOTTI, F. Infancia en riesgo social y políticas sociales en Chile: desarrollo y perspectivas del Servicio Nacional de Menores y su relación con las políticas sociales, la sociedad civil y el marco jurídico. Montevideo: Instituto Interamericano del niño, 1994.

PMRP, Secretaria da Fazenda. Balanço Orçamentário. Exercícios de 1993 a 1999.

PMRP/SCDS, Serviços prestados pela SCDS. Ribeirão Preto, mimeo, 2000.

PMRP/SCDS, Relatório técnico de atividades. Ribeirão Preto, mimeo, 1999.

PMRP/SEBES, Rede criança: o atendimento à criança e ao adolescente. Ribeirão Preto, Prefeitura Municipal de Ribeirão Preto, 1995.

PMRP/SEBES, Relatório técnico de atividades. Ribeirão Preto, mimeo, 1995.

POULANTZAS, N. Sobre el estado capitalista. Barcelona: Laia, 1977.

PSDB, Manifesto. Em Diário Oficial da União, Brasília, Seção I, 6 de julho de 1988: 12507-12508, 1988.

PSDB, Programa do PSDB: diretrizes políticas. Em Diário Oficial da União, Brasília, Seção I, 6 de julho de 1988 : 12508-12510, 1988

PSDB, Programa de Governo da Frente Social Democrática de Ribeirão Preto. Ribeirão Preto, mimeo, 1996.

PT, Manifesto. Partido dos Trabalhadores. São Paulo, Mimeo, 1980.

PT, Programa. Partido dos Trabalhadores. São Paulo, Mimeo, 1980.

PT, Programa de governo. Frente Popular e Democrática de Ribeirão Preto. Ribeirão Preto, mimeo,1992.

ROSEMBERG, F. Políticas sociais para crianças e adolescentes e avaliação. Em UNICEF, Avaliação de Programas de Atendimento a crianças em situação de risco. Projeto Roda Viva, Rio de Janeiro, mimeo, 1994.

SILVA, I.L.F. Reforma ou contra-reforma no sistema de ensino do estado do Paraná? Uma análise da meta da igualdade social nas políticas educacionais dos anos 90. 1998, Dissertação de mestrado, FE-USP, São Paulo.

VIANA, A.L. Abordagens metodológicas em políticas públicas: revisão bibliográfica. Cadernos de pesquisa do NEPP, Campinas, 5, 1-104, 1988

VIANNA, M.L.W. Política versus economia: notas (menos pessimistas) sobre a globalização de Bem-estar. Em S. GERSCHMAN, e M.L.W. VIANNA, A miragem da pós-modernidade: democracia e políicas sociais no contexto da globalização. Rio de Janeiro: Ed. Fiocruz, 1997. 